\title{
Pricing and Ordering Decisions in a Retailer Dominant Channel Involving a Third-Party Logistics Provider
}

\author{
Xiaoxu Chen, ${ }^{1}$ Peng Xu $\left(\mathbb{D},{ }^{2,3}\right.$ Thomas Walker, ${ }^{3}$ and Shengzhong Huang ${ }^{2}{ }^{2}$ \\ ${ }^{1}$ School of Economics and Management, Shanxi University, Taiyuan, 030006, China \\ ${ }^{2}$ School of Business, Southwest University of Political Science and Law, Chongqing 401120, China \\ ${ }^{3}$ John Molson School of Business, Concordia University, Montreal H3G 1M8, Canada \\ Correspondence should be addressed to Peng Xu; xupengswul@163.com
}

Received 8 December 2018; Accepted 19 May 2019; Published 10 July 2019

Academic Editor: Yu-Wang Chen

Copyright (C) 2019 Xiaoxu Chen et al. This is an open access article distributed under the Creative Commons Attribution License, which permits unrestricted use, distribution, and reproduction in any medium, provided the original work is properly cited.

\begin{abstract}
This paper theoretically investigates pricing and ordering decisions in a supply chain system comprised of a dominant retailer, a manufacturer, and a third-party logistics (3PL) provider. The paper introduces the logistics service level as an additional variable and obtains the equilibrium pricing and ordering decisions of the supply chain members by applying game theory. Our analysis focuses on the effects of three sensitivity coefficients, i.e., the retailer's order quantity to the manufacturer's wholesale price, the 3PL's logistics service price, and the logistics service level on equilibrium decisions. In addition, we explore the effect of the logistics investment cost and the market risk on equilibrium decisions. Finally, we present a numerical illustration to validate our theoretical results and explore their effects on channel performance.
\end{abstract}

\section{Introduction}

In order to focus resources and capital on their core business, many companies outsource their noncore business, such as transportation, warehousing, freight consolidation and distribution, as well as labeling and packaging to a third party logistics service provider (3PL) $[1,2]$. The $3 \mathrm{PL}$ can reduce companies' logistics costs, help companies improve customer satisfaction, thereby increasing the market demand for their products, and finally increase their sales revenue [3]. Many research articles have shown that improvements in the logistics service level can increase customer satisfaction and order quantity $[4,5]$. Today, the retail industry is increasingly dominated by large, centrally managed "power retailers" [6]. Many large retail companies, such as Gome (China), Suning (China), Wal-Mart (USA), and Carrefour (France), begin to gradually control sales channels in the supply chain. In the supply chain, the term "dominant" refers to a member who has the power to control or influence another member's decisions [7]. Many such dominant retailers outsource their logistics service to the 3PL. For example, Wal-Mart in the US outsources its logistics to a professional 3PL company in
China named Li \& Fung of Hong Kong. Gome, a retailer that sells a variety of electronics products in China, outsources the cell phone's logistics service to DTW Logistics, which results in a $20 \%$ decrease in cost [8]. The 3PL's logistics service level directly affects the retailer's order quantity and affects its profits. Therefore, the three-echelon supply chain composed of one manufacturer, one 3PL, and one retailer is ubiquitous. Research on the logistics service level demonstrates that the order quantity in a three-echelon supply chain has theoretical and practical significance and can provide a basis for the decision-making of the retail business.

Based on the important application of the supply chain with dominant retailers in modern society, this paper studies the three-level supply chain system consisting of a dominant retailer, a manufacturer, and a third-party logistics (3PL) provider. This paper, taking the logistics service level as an additional variable, aims to analyze its effect on ordering and pricing decisions for supply chain members based on logistics service outsourcing. We wish to provide answers for the following questions:

(1) How can one determine the optimal ordering and/or pricing decisions for supply chain members in the 
presence of a dominant retailer and logistics service outsourcing?

(2) How does the logistics service level affect the equilibrium pricing and ordering decisions for the supply chain members?

(3) How do other factors, such as the logistics investment cost and market risk, affect the equilibrium pricing and ordering decisions for the supply chain members?

The remainder of this paper is organized as follows. In Section 2, we briefly present the related theoretical and behavioral literature review. We provide details of our model and state our assumptions in Section 3. Section 4 provides an analysis of the basic model, including an optimal pricing and service level decisions model for the 3PL in Section 4.1, an optimal pricing decisions for the manufacturer model in Section 4.2, an optimal ordering decision model for the retailer in Section 4.3, and an equilibrium model for pricing and ordering decisions of the supply chain members in Section 4.4. In Section 5, we present numerical examples to provide some managerial insights. Finally, we conclude this paper with a discussion and some managerial insights in Section 6.

\section{Literature Review}

Our study is closely related to the extant research stream on quantitative ordering and pricing decision models that considers logistics outsourcing by supply chain members and supply chain decisions with a dominant retailer. The literature is briefly reviewed below.

With the rapid development of the logistics industry, research on supply chain optimization for quantitative ordering and pricing decisions under logistics outsourcing has received wide attention. Some scholars have introduced 3PL into a supply chain composed of a retailer and a manufacturer and studied the resulting ordering and pricing decisions. For example, Lei et al. investigate supplier-buyer channel coordination policies involving a 3PL provider with concave cost functions and analyze the impact of coordination policies on supply chain profitability [9]. Similarly, Woo et al. study the ordering decision in a three-echelon supply chain under logistics outsourcing [10]. Li et al. examine optimization decisions in a supply chain system with one 3PL, one supplier, and one retailer and analyze the effect of double marginalization on pricing policies $[11,12]$. The supply chain structure is also used in this paper, but the studies mentioned above do not consider a dominant retailer and the impact of the logistics service level. Other scholars have also studied decisions under situations of capital constraints or competitive environment involving a 3PL, which can lead to future research based on this paper. For example, Chen and Xie explore the supply chain decisions with a 3PL and analyze the integration value of 3PL's logistics and financial functions [13]. Chen and Cai investigate an extended supply chain model with a supplier, a budget-constrained retailer, a bank, and a 3PL provider, in which the retailer has an insufficient initial budget and may borrow or obtain trade credit from either a bank (traditional role) or a 3PL provider (control role) [14]. Jiang et al. investigate decisions and coordination policies in a supply chain-wide system consisting of a manufacturer, a third-party logistics (3PL) provider, and two competing retailers [15].

Importantly, the research above does not consider the impact of the logistics service level on supply chain decisions. Among the research that considers the impact of the logistics service level, Lim studies how to design a contract to motivate the 3PL business to tell the truth, when the 3PL's logistics service quality and cost are private information [16]. Wu et al. study an outsourced logistics channel where a distributor procures a quantity of a fresh produce and outsources his logistics operations to a 3PL [17]. The studies above are based on a two-echelon supply chain established by the 3PL and the outsourcing company. In the three-echelon supply chain involving a 3PL, Cai et al. consider a producer's fresh produce supply through a 3PL to a distant market where a distributor purchases and sells it to the end consumers [18]. Jiang et al. investigate logistics costs shared in two kinds of supply chains, including a one manufacturer 3PL provider retailer supply chain and a two manufacturer 3PL provider retailer supply chain without considering the pricing decisions of products [8]. As valuable as the studies are, they do not address the possible presence of a dominant retailer.

The logistics service level is very important for the decision-making of supply chain members, and the dominant position of the supply chain members leads to different decisions. A significant amount of research has been done on retailer dominant supply chain decisions. In these studies, some demand functions are deterministic, such as references $[6,19-21]$, while others are stochastic, such as references [7, 22-24]. Allowing for deterministic demand, Chen and Xiao study a supply chain model consisting of a manufacturer, a dominant retailer, and many smaller scale retailers that are not dominant, and investigate mechanism coordination under demand disruption [19]. Choi et al. investigate a closed-loop supply chain which consists of a retailer, a collector, and a manufacturer, and examine the performance of a different closed-loop supply chain under different channel leadership [20]. In a model that assumes stochastic demand, Hua and Li analyze two cooperative scenarios, in which the Nash bargaining model is utilized to implement profit sharing between the manufacturer and the dominant retailer [7]. Finally, $\mathrm{Hu}$ et al. study a supplier's optimal decision-making under a retailer's profit margin constraint and the effect of that constraint on supply chain coordination [23]. In practice, demands for most products are stochastic. This study is based on stochastic demand.

In conclusion, retailer dominance and the logistics service level are both important factors that affect the supply chain members' decision-making. The supply chain, comprised of the manufacturers, the retailers, and the $3 \mathrm{PL}$, is widespread in practical business. Investigating the decisions of threeechelon supply chain members under the influence of a dominant retailer and the logistics service level has obvious practical significance. No research has investigated this problem until now. To the best of our knowledge, the only paper that combines and explores a 3PL in a supply chain 


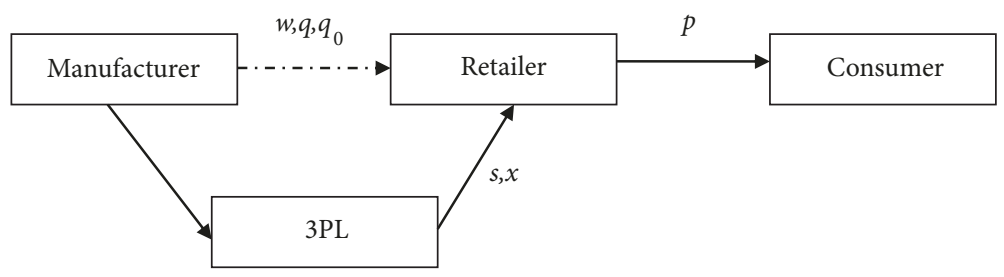

FIGURE 1: The relationship among supply chain members when including the logistics service level.

under retailer dominance is Jiang et al. [15]. Our paper differs from their investigation in the following aspects: first, the market demand is stochastic in our study rather than deterministic in their paper. Second, our paper introduces the logistics service level into the retailer dominant supply chain and establishes a three-echelon supply chain model including one manufacturer, one 3PL, and one dominant retailer and analyzes its effect on the decisions of supply chain members. Third, our paper investigates the effects of the retailer's order quantity sensitivity to the manufacturer's wholesale price, the effects of the 3PL's logistics service price on the equilibrium behavior and performance, and the effects of the logistics investment cost and the market risk on the equilibrium behavior and performance.

\section{Problem Description and Assumptions}

3.1. Problem Description. Consider a three-echelon supply chain with one manufacturer, one 3PL, and one retailer with a dominant position in the channel who faces a stochastic demand market. Their relationship is shown in Figure 1, where the manufacturer provides the product to the retailer and the retailer then sells it to the consumer. The manufacturer and the retailer outsource the product's logistics service, such as transportation and packaging, to a professional 3PL where the service level of the 3PL affects the product's ordering quantity. The retailer's dominant position affects the optimal decisions of other supply chain members [25]. Following the definition of retailer dominance [26, 27], we assume that the retailer has the ability to influence the manufacturer's wholesale price and the 3PL's logistics service price and level by setting his/her potential maximum order quantity and announcing the sensitivity of his/her order quantity to the manufacturer's wholesale price. The manufacturer also influences the 3PL's logistics price and level. Therefore, suppose $q=q_{0}-\alpha w-\beta s+\gamma x$, in which the parameter $q_{0}$ is the retailer's maximum order quantity considering the retail-market conditions when he/she outsources the logistics service to the 3PL; the parameters $\alpha>0, \beta>0$, and $\gamma>0$ are the sensitivities of the retailer's order quantity $q$ to the manufacturer's wholesale price $w$, the 3PL's logistics service price $s$, and level $x$, respectively. The model suggests that when other conditions are held equal, if the manufacturer or the 3PL increases his/her price, then the retailer's ordering quantity will decrease. At the same time, if the 3PL improves his/her service level, then the retailer's ordering quantity will increase. This means that the dominant retailer can threaten other supply chain members (the 3PL and the manufacturer).
If any of the two supply chain members increases his/her price, it will reduce the retailer's ordering quantity, which will then cause the manufacturer's and the 3PL's profits to decline. However, any improvement in the 3PL's logistics service level will encourage the retailer to increase the ordering quantity, leading to an increase in the 3PL's profit.

3.2. Model Assumptions. In this paper, we make the following assumptions:

(1)The retailer orders products in wholesale form, the residual value of the product that is not sold during the cycle is zero, and no return is allowed

(2) The 3PL, the manufacturer, and the retailer are all risk neutral

(3) All supply chain members have symmetric information; i.e., the manufacturer and the 3PL have complete information regarding the demand of the retailer, the retailer and the 3PL have complete information about the cost of the manufacturer, and the retailer and the manufacturer have complete information regarding the cost of the 3PL

(4) The retail-market demand $d$ for the single-period product follows a uniform distribution $\left[I_{1}, I_{2}\right]\left(0<I_{1}<\right.$ $\left.I_{2}\right)$, where $f(x)$ and $F(x)$ are the probability density function (PDF) and the cumulative distribution function (CDF) associated with $d$, respectively, the finite mean and standard deviation are, respectively, $\mu, \sigma(\mu>0, \sigma>0)$, and we have $I_{1}=\mu-\sqrt{3} \sigma, I_{2}=\mu+\sqrt{3} \sigma$

(5) The 3PL's transport capacity is unlimited

(6) The retailer's shortage loss is not considered

In addition, we define other symbols in this paper as follows:

$c_{L}$ is the unit product's logistics service cost borne by the 3PL

$c_{M}$ is the unit production cost borne by the manufacturer

$c_{R}$ is the unit selling cost borne by the retailer

$p$ is the unit retail price at which the retailer sells to the consumer

$m$ is the logistics investment cost the 3PL bears to improve the logistics service level

Finally, we define the decision symbols in this paper as follows:

$q$ is the retailer's ordering quantity

$w$ is the unit wholesale price the manufacture charges the retailer 
$s$ is the logistics service price the 3PL charges the retailer

$x$ is the logistics service level the $3 \mathrm{PL}$ provides

We assume that the residual value of products not sold is zero in a single-period, and we do not consider the retailer's shortage loss. Furthermore, we assume that the retailer's profit in one cycle is equal to its total revenue minus the sum of its ordering cost, logistics cost, and retail cost:

$$
\begin{aligned}
& \pi_{r} \\
& = \begin{cases}p d-\left(w+s+c_{R}\right)\left(q_{0}-\alpha w-\beta s+\gamma x\right), & d \leq q \\
\left(p-\left(w+s+c_{R}\right)\right)\left(q_{0}-\alpha w-\beta s+\gamma x\right), & d>q .\end{cases}
\end{aligned}
$$

The equation above describes two situations: first, when the demand is less than or equal to the order quantity, i.e., $d \leq q$, the products will be oversupplied, resulting in a backlog due to the short life cycle of the product. The value of the backlog of goods is zero, and at this time the retailer's profit in one cycle is equal to its total revenue of sold products (that is, the market demand) minus the sum of his/her purchase cost, logistics cost, and selling cost. When the demand is greater than the order quantity, i.e., $d>q$, the products' market demand exceeds the supply. All the ordered products are sold, and at this time the retailer's profit in one cycle is equal to its total revenue of sold products (that is, the ordered quantity) minus the sum of his/her purchase cost, logistics cost, and selling cost.

Therefore, the retailer's expected profit is

$$
\begin{aligned}
E \pi_{r}= & \left(p-(w+s)-c_{R}\right)\left(q_{0}-\alpha w-\beta s+\gamma x\right) \\
& -p \int_{-\infty}^{q}\left(q_{0}-\alpha w-\beta s+\gamma x-y\right) f(y) d y
\end{aligned}
$$

The manufacturer's profit is equal to the total revenue charged to the retailer minus the corresponding production cost, that is,

$$
\pi_{m}=\left(w-c_{M}\right)\left(q_{0}-\alpha w-\beta s+\gamma x\right)
$$

Similarly, the 3PL's profit in one cycle is equal to the total logistics revenue minus the sum of corresponding logistics and investment costs. Similar to Han et al. [28], assuming the logistics investment cost coefficient is $m x^{2}$ when the logistics service level is $x$, the 3PL's profit is

$$
\pi_{l}=\left(s-c_{L}\right)\left(q_{0}-\alpha w-\beta s+\gamma x\right)-m x^{2}
$$

The supply chain members (the manufacturer, the 3PL, and the retailer) make their decisions by using a dynamic game to maximize their own profits. Here, the dynamic game means that, in the first stage, the retailer determines the product's maximum order quantity $q_{0}$ and the sensitivity of the order quantity to the wholesale price and the logistics service price and level, to maximize his/her own profit. In the second stage of the game, the manufacturer offers the wholesale price $w$ charged to the retailer to maximize his/her own profit. In the last stage of the game, the 3PL determines his/her logistics service price $s$ charged to the retailer and the corresponding logistics service level $x$ to maximize his/her own profit. Therefore, the general optimization model can be described as

$$
\begin{array}{ll}
\max & E \pi_{r}=\left(p-\left(w+s+c_{R}\right)\right)\left(q_{0}-\alpha w-\beta s+\gamma x\right) \\
& -p \int_{-\infty}^{q}\left(q_{0}-\alpha w-\beta s+\gamma x-y\right) f(y) d y, \\
\text { s.t. } & \max \pi_{m}=\left(w-c_{M}\right)\left(q_{0}-\alpha w-\beta s+\gamma x\right), \\
\text { s.t. } & \max \pi_{l}=\left(s-c_{L}\right)\left(q_{0}-\alpha w-\beta s+\gamma x\right)-m x^{2}
\end{array}
$$

\section{The Basic Model}

4.1. Optimal Pricing and Service Level Decisions for the 3PL. With the participation of the 3PL, the manufacturer and the retailer will transfer the product through the $3 \mathrm{PL}$. The profit function of the $3 \mathrm{PL}$ is as shown in (4). Applying the first-order conditions to the resulting profit function in terms of the 3PL's logistics service price $s$ and the logistics service level $x$, we obtain the following derivatives:

$$
\begin{aligned}
& \frac{\partial \pi_{l}}{\partial s}=q_{0}-\alpha w-\beta s+\gamma x-\beta\left(s-c_{L}\right), \\
& \frac{\partial \pi_{l}}{\partial x}=\left(s-c_{L}\right) \gamma-2 m x .
\end{aligned}
$$

By solving the equations $\left\{\partial \pi_{l} / \partial x=0 ; \partial \pi_{l} / \partial s=0\right\}$, we obtain the functions of the 3PL's logistics service price $s$ and the logistics service level $x$, respectively, as

$$
\begin{aligned}
& s^{*}=c_{L}+\frac{2 m\left(q_{0}-\alpha w-\beta c_{L}\right)}{4 \beta m-\gamma^{2}} \\
& x^{*}=\frac{\gamma\left(q_{0}-\alpha w-\beta c_{L}\right)}{4 \beta m-\gamma^{2}}
\end{aligned}
$$

Substituting (7) and (8) into (4) and simplifying, (4) can be written as

$$
\pi_{l}=\frac{m\left(q_{0}-\alpha w-\beta c_{L}\right)^{2}}{4 \beta m-\gamma^{2}} .
$$

To guarantee that the results above have practical significance, the equation should be positive, i.e., $\pi_{l}>0$; hence $4 \beta m-\gamma^{2}>0$, i.e., $m>\gamma^{2} / 4 \beta$. Otherwise, the lower investment cost will cause the $3 \mathrm{PL}$ to reduce the logistics service level to maximize his/her profit, which will result in a loss for the 3PL, and thus the 3PL will exit the market. If $m>$ $\gamma^{2} / 4 \beta$, the Hessian matrix $\left[\begin{array}{cc}\partial^{2} \pi_{l} / \partial x^{2} & \partial^{2} \pi_{l} / \partial x \partial s \\ \partial^{2} \pi_{l} / \partial s \partial x & \partial^{2} \pi_{l} / \partial s^{2}\end{array}\right]=\left[\begin{array}{cc}-2 m & \gamma \\ \gamma & -2 \beta\end{array}\right]$ will be negative; therefore (7) and (8) are optimal functions of the 3PL's logistics service price and service level.

Similarly, to ensure that the logistics service price and logistics service level have practical significance, they should both be positive. Therefore, $q_{0}-\alpha w-\beta c_{L}>0$.

Eqs. (7) and (8) indicate that the lower logistics investment costs can improve the logistics service level $m$, leading to the higher logistics service price $s$ and logistics service 
level $x$. Additionally, given that $\partial \pi_{l} / \partial x=0$, we can derive $x^{*}=(\gamma / 2 m) s^{*}-\gamma c_{L} / 2 m$. Therefore, we suggest the following propositions.

Proposition 1. The higher the logistics service level, the higher the logistics service price. The relationship between the logistics investment cost and the logistics service level should satisfy $m>$ $\gamma^{2} / 4 \beta$. Otherwise, the logistics investment cost is too low, which will make the 3PL decrease the logistics service level and result in a loss.

Proposition 1 demonstrates that to obtain a higher logistics service level, the retailer needs to pay a higher logistics price. This is because any improvement in the logistics service requires the 3PL to make a certain investment. Therefore, if the 3PL improves the logistics level, the cost of the logistics service increases, and the 3PL can only compensate the increasing logistics cost by increasing his/her logistics price. Moreover, the equation $q=q_{0}-\alpha w-\beta s+\gamma x$ indicates that the retailer's ordered quantity is increasing in the logistics service level but decreasing in the logistics price. Proposition 1 shows that the higher the logistics service level, the higher the logistics service price. Therefore, the retailer needs to balance the value of the logistics service price and the logistics service level to determine the optimal order quantity to maximize his/her own profit. The logistics investment cost to improve the logistics service level should satisfy $m>\gamma^{2} / 4 \beta$. Otherwise, the logistics investment cost is too low, and the 3PL will decrease the logistics service level, which results in a loss. From another point of view, the inequality $m>\gamma^{2} / 4 \beta$ is equivalent to $\beta>\gamma^{2} / 4 m$. The sensitivity coefficient of the order quantity to the 3PL's logistics service price should be more than a certain ratio of the sensitivity coefficient of the ordering quantity to the 3PL's logistics service level.

4.2. Optimal Pricing Decisions for the Manufacturer. The profit function of the manufacturer is as shown in (3). Substituting (7) and (8) into (3) and applying the first-order and second-order conditions to the profit function in terms of the wholesale price $w$, we obtain the following derivatives:

$$
\begin{aligned}
\frac{\partial \pi_{m}}{\partial w} & =\frac{2 \beta m\left(q_{0}-\left(2 w-c_{M}\right) \alpha-c_{L} \beta\right)}{4 \beta m-\gamma^{2}}, \\
\frac{\partial^{2} \pi_{m}}{\partial w^{2}} & =-\frac{4 \alpha \beta m}{4 \beta m-\gamma^{2}} .
\end{aligned}
$$

Since $m>\gamma^{2} / 4 \beta, \partial^{2} \pi_{m} / \partial w^{2}<0$, it meets the optimality conditions. Therefore, we derive the optimal wholesale price of the manufacturer as

$$
w^{*}=\frac{\left(q_{0}-\beta c_{L}\right)+c_{M} \alpha}{2 \alpha}
$$

4.3. Optimal Ordering Decisions for the Retailer. The profit function of the retailer is shown in (2). Substituting (7), (8), and (11) into (2) and applying the first-order and secondorder conditions to the profit function in terms of the maximum order quantity $q_{0}$, we obtain the following derivatives:

$$
\begin{aligned}
\frac{\partial E \pi_{r}}{\partial q_{0}}= & \frac{\sqrt{3} \beta m p \alpha\left(m c_{M} \beta \alpha+\beta\left(c_{L} \beta-q_{0}+4 \mu\right) m-\mu \gamma^{2}\right)+36 m^{2} \alpha^{2} \beta \sigma c_{M}}{6 \sigma \alpha\left(4 \beta m-\gamma^{2}\right)^{2}} \\
& +\frac{6 \sigma m \beta\left(2\left(p-c_{L}-2 c_{R}\right) \beta-q_{0}\right) m-6 \sigma m \beta\left(q_{0}-\beta c_{L}\right)\left(4 \beta m-\gamma^{2}\right)}{6 \sigma \alpha\left(4 \beta m-\gamma^{2}\right)^{2}}-\frac{3 \gamma^{2}\left(p-2 c_{L}-2 c_{R}\right)}{6 \sigma \alpha\left(4 \beta m-\gamma^{2}\right)^{2}} \\
\frac{\partial^{2} E \pi_{r}}{\partial q_{0}^{2}}= & -\frac{\beta m\left(4 \sqrt{3} \alpha \beta m p+24 \sigma\left(2 m \alpha+4 \beta m-\gamma^{2}\right)\right)}{6 \sigma \alpha\left(4 \beta m-\gamma^{2}\right)^{2}}
\end{aligned}
$$

Because $\partial^{2} E \pi_{r} / \partial q_{0}^{2}<0$, it meets the optimality conditions. Therefore, solving $\partial E \pi_{r} / \partial q_{0}=0$, we can derive the maximum order quantity of the retailer as

$$
\begin{aligned}
& q_{0}^{*} \\
& =\frac{\alpha\left(\sqrt{3} p \mu+3\left(p-2\left(c_{R}+c_{M}+c_{L}\right)\right) \sigma\right)\left(4 \beta m-\gamma^{2}\right)}{\alpha \beta m p \sqrt{3}+6 \sigma\left(2 m \alpha+4 \beta m-\gamma^{2}\right)} \\
& \quad+\alpha c_{M}+\beta c_{L}
\end{aligned}
$$

4.4. Equilibrium Pricing and Ordering Decisions for the Supply Chain Members. In the three-echelon supply chain game, the retailer first chooses the maximum order quantity according to (13), and then the manufacturer determines the optimal wholesale price $w^{*}$ based on $q_{0}^{*}$. Next, the 3PL decides the optimal logistics service price $s^{*}$ and logistics service level $x^{*}$ according to the decisions $q_{0}^{*}$ and $w^{*}$. At last, the retailer determines the optimal order quantity $q^{*}$ based on $q_{0}^{*}, w^{*}, s^{*}$, and $x^{*}$.

Firstly, by substituting (13) into (11) and simplifying the equation, the manufacturer's optimal wholesale price can be expressed as

$$
\begin{aligned}
& w^{*} \\
& =\frac{\left(4 \beta m-\gamma^{2}\right)\left(\sqrt{3} \mu p+3\left(p-2\left(c_{R}+c_{M}+c_{L}\right)\right) \sigma\right)}{2\left(\alpha \beta m p \sqrt{3}+6\left(2 \alpha m+4 \beta m-\gamma^{2}\right) \sigma\right)} \\
& \quad+c_{M}
\end{aligned}
$$


Then, by substituting (13) and (14) into (7) and (8), the 3PL's optimal service price and level can be derived as

$$
\begin{aligned}
& s^{*}=c_{L}+\frac{\alpha m\left(\sqrt{3} \mu p+3\left(p-2\left(c_{R}+c_{M}+c_{L}\right)\right) \sigma\right)}{\alpha \beta m p \sqrt{3}+6\left(2 \alpha m+4 \beta m-\gamma^{2}\right) \sigma} \\
& x^{*}=\frac{\alpha \gamma\left(\sqrt{3} \mu p+3\left(p-2\left(c_{R}+c_{M}+c_{L}\right)\right) \sigma\right)}{2\left(\alpha \beta m p \sqrt{3}+6\left(2 \alpha m+4 \beta m-\gamma^{2}\right) \sigma\right)}
\end{aligned}
$$

At last, by substituting (13), (14), (15), and (16) into $q=q_{0}-$ $\alpha w-\beta s+\gamma x$, the retailer's optimal order quantity can be derived as

$$
q^{*}=\frac{\alpha \beta m\left(\sqrt{3} \mu p+3\left(p-2\left(c_{R}+c_{M}+c_{L}\right)\right) \sigma\right)}{\alpha \beta m p \sqrt{3}+6\left(2 \alpha m+4 \beta m-\gamma^{2}\right) \sigma}
$$

To guarantee that the results above have practical significance, each variable should be positive. For (14) to (17) and $m>\gamma^{2} / 4 \beta, 4 \beta m-\gamma^{2}>0$, if the optimal order quantity $q^{*}>0$, then the maximum order quantity $q_{0}{ }^{*}$, the optimal wholesale price $w^{*}$, the optimal logistics service price $s^{*}$, and the optimal logistics service level $x^{*}$ would be positive. This is because when the order quantity is positive, the maximum order quantity is greater than the optimal order quantity. Under this situation, the manufacturers and the $3 \mathrm{PL}$ will obtain a profit, and their pricing will be meaningful. Here, the 3PL's logistics service level is also positive. To guarantee that the order quantity $q^{*}>0$, it needs to meet the following inequality condition:

$$
\sqrt{3} p \mu+3\left(p-2\left(c_{R}+c_{M}+c_{L}\right)\right) \sigma>0
$$

where each variable is positive. Thus, when $p>2\left(c_{R}+c_{M}+\right.$ $\left.c_{L}\right)$, (18) always holds. This means that when the product sales price is two times higher than the total cost of the system, the retailer is profitable, and he/she will buy the products.

When $p<2\left(c_{R}+c_{M}+c_{L}\right)$, to guarantee that the retailer's ordered quantity is positive, the following inequality should be satisfied: $\mu / \sigma>\sqrt{3}\left(2\left(c_{R}+c_{M}+c_{L}\right)-p\right) / p$. This shows that when the profit of the retailer is low, to guarantee that the order quantity is positive, the average product demand of the market must be several times greater than the market fluctuation, as shown by $\mu>\left(\sqrt{3}\left(2\left(c_{R}+c_{M}+c_{L}\right)-p\right) / p\right) \sigma$. In doing so, the retailer will buy the products.

Furthermore, by analyzing the effect of $m, \gamma, \alpha, \beta$, and $\sigma$ on the supply chain equilibrium decisions, we make the following proposition.

Proposition 2. With an increase in $m$, the logistics service price and level of the $3 P L$, the order quantity of the retailer decreases while the wholesale price of the manufacturer and the maximum order quantity of the retailer increase. Therefore, government subsidies for improving the logistics service can effectively increase the 3PL's enthusiasm and increase the logistics service price and level.
Proof. Based on inequality (18), we can get the following derivatives:

$$
\begin{aligned}
& \frac{\partial q_{0}{ }^{*}}{\partial m} \\
& =\frac{(12 \sigma+\beta p \sqrt{3})\left(\sqrt{3} p \mu+3\left(p-2\left(c_{R}+c_{M}+c_{L}\right)\right) \sigma\right) \alpha^{2} \gamma^{2}}{\left(\alpha \beta m p \sqrt{3}+6 \sigma\left(2 m \alpha+4 m \beta-\gamma^{2}\right)\right)^{2}} \\
& >0, \\
& \frac{\partial q^{*}}{\partial m}=-\frac{6\left(\sqrt{3} p \mu+3\left(p-2\left(c_{R}+c_{M}+c_{L}\right)\right) \sigma\right) \beta \alpha \gamma^{2} \sigma}{\left(\alpha \beta m p \sqrt{3}+6 \sigma\left(2 m \alpha+4 m \beta-\gamma^{2}\right)\right)^{2}}<0, \\
& \frac{\partial s^{*}}{\partial m}=-\frac{6\left(\sqrt{3} p \mu+3\left(p-2\left(c_{R}+c_{M}+c_{L}\right)\right) \sigma\right) \alpha \gamma^{2} \sigma}{\left(\alpha \beta m p \sqrt{3}+6 \sigma\left(2 m \alpha+4 m \beta-\gamma^{2}\right)\right)^{2}}<0, \\
& \frac{\partial x^{*}}{\partial m} \\
& =-\frac{(\alpha \beta p \sqrt{3}+12(\alpha+\beta) \sigma)}{2\left(\alpha \beta m p \sqrt{3}+6 \sigma\left(2 m \alpha+4 m \beta-\gamma^{2}\right)\right)^{2}} \\
& \cdot\left(\sqrt{3} p \mu+3\left(p-2\left(c_{R}+c_{M}+c_{L}\right)\right) \sigma\right) \gamma \alpha<0, \\
& \frac{\partial w^{*}}{\partial m} \\
& =\frac{(\beta p \sqrt{3}+12 \sigma)\left(\sqrt{3} p \mu+3\left(p-2\left(c_{R}+c_{M}+c_{L}\right)\right) \sigma\right) \alpha \gamma^{2}}{2\left(\alpha m p \sqrt{3}+6 \sigma\left(2 m \alpha+4 m \beta-\gamma^{2}\right)\right)^{2}} \\
& >0 .
\end{aligned}
$$

Proposition 2 shows that if $m$ is higher, i.e., higher investment is needed to improve unit logistics service level, then the 3PL will reduce the logistics service level to improve its own profits, and the logistics service price will decrease. Although the reduction of the logistics service level will reduce the retailer's maximum order quantity, the reduction in the logistic cost will increase it. Their combined effect increases the retailer's maximum order quantity, which gives the manufacturer a chance to increase the price. Therefore, the manufacturer will increase his/her wholesale prices. The increase in the optimal order quantity and the decrease in the logistics service price lead to an increase in the maximum order quantity; however, the increase of the wholesale price and the reduction of the logistics level decrease the maximum order quantity, and the decrease exceeds the increase. Therefore, the final order quantity of the retailer is also reduced. At the same time, if the government increases its investment subsidy to improve the logistics service, it will share the cost of the 3PL to improve the logistics service. At this point, the 3PL's investments cost at improving the logistics service will reduce, and the 3PL will more actively improve the logistics service level to increase its service price, which will also increase the retailer's order quantity. The increase in the order quantity will reduce the wholesale price, which is also beneficial to the $3 \mathrm{PL}$ and the retailers. For the 3PL, if the logistics service level is increased, the order quantity of the retailer will increase and the wholesale price of the manufacturer will reduce. 
However, the increase in the order quantity can make up for the reduction in wholesale prices, which is favorable for the supply chain participants. Therefore, it can improve the enthusiasm of the enterprises and promote the development of the social economy.

Proposition 3. With an increase in $\gamma$, the logistics service price, the logistics service level, and the order quantity of the retailer increase while the maximum order quantity of the retailer and the wholesale price of the manufacturer decrease.

Proof. Based on inequality (18), we can obtain the following derivatives:

$$
\begin{aligned}
& \frac{\partial q_{0}{ }^{*}}{\partial \gamma} \\
& =-\frac{2(12 \sigma+\beta p \sqrt{3})\left(\sqrt{3} p \mu+3\left(p-2\left(c_{R}+c_{M}+c_{L}\right)\right) \sigma\right) \alpha^{2} \gamma m}{\left(\alpha \beta m p \sqrt{3}+6 \sigma\left(2 m \alpha+4 m \beta-\gamma^{2}\right)\right)^{2}} \\
& <0, \\
& \frac{\partial q^{*}}{\partial \gamma}=\frac{12\left(\sqrt{3} p \mu+3\left(p-2\left(c_{R}+c_{M}+c_{L}\right)\right) \sigma\right) \beta \alpha \gamma \sigma}{\left(\alpha \beta m p \sqrt{3}+6 \sigma\left(2 m \alpha+4 m \beta-\gamma^{2}\right)\right)^{2}}>0, \\
& \frac{\partial s^{*}}{\partial \gamma}=\frac{12\left(\sqrt{3} p \mu+3\left(p-2\left(c_{R}+c_{M}+c_{L}\right)\right) \sigma\right) \alpha \gamma m \sigma}{\left(\alpha \beta m p \sqrt{3}+6 \sigma\left(2 m \alpha+4 m \beta-\gamma^{2}\right)\right)^{2}}>0, \\
& \frac{\partial x^{*}}{\partial \gamma} \quad \cdot \quad \frac{\left(\alpha \beta m p \sqrt{3}+6 \sigma\left(2 m \alpha+4 m \beta+\gamma^{2}\right)\right)}{2\left(\alpha \beta m p \sqrt{3}+6 \sigma\left(2 m \alpha+4 m \beta-\gamma^{2}\right)\right)^{2}} \\
& \quad \cdot\left(\sqrt{3} p \mu+3\left(p-2\left(c_{R}+c_{M}+c_{L}\right)\right) \sigma\right) \alpha>0 \\
& \frac{\partial w^{*}}{\partial \gamma} \\
& =-\frac{(\beta p \sqrt{3}+12 \sigma)\left(\sqrt{3} p \mu+3\left(p-2\left(c_{R}+c_{M}+c_{L}\right)\right) \sigma\right) \alpha \gamma m}{2\left(\alpha \beta \sqrt{3}+6 \sigma\left(2 m \alpha+4 m \beta-\gamma^{2}\right)\right)^{2}} \\
& <0 .
\end{aligned}
$$

Proposition 3 shows that if an improvement in the 3PL's unit logistics service level can increase the order quantity of the retailer, then the $3 \mathrm{PL}$ will increase the logistics service level to increase his/her profit, and the logistics service price will increase. Although the improvement of the logistics service level will increase the maximum order quantity of the retailer, the increase of the logistic price will reduce it. The combined effect leads to a reduction in the maximum order quantity of the retailer, which causes the manufacturer to reduce the wholesale prices to prevent a reduction in the final order quantity. Therefore, the manufacturer will reduce the wholesale prices. The increase in the optimal order quantity caused by the reduction in the wholesale prices and the improvement of the logistics service level can make up for its reduction caused by the reduction in the maximum order quantity and the increase of the logistics price. Therefore, the final order quantity of the retailer is also reduced. In reality, if we heighten the logistics service level, then the transportation time for perishable goods such as fresh fruit will be shortened, which will keep the goods fresh, and the order quantity of the retailer will increase. Therefore, if customers are more sensitive to the logistics service level, the $3 \mathrm{PL}$ is willing to pay more to improve that level.

Proposition 4. With an increase in $\alpha$, the wholesale price of the manufacturer decreases, the logistics service price, the logistics service level, the order quantity, and maximum order quantity of the retailer increase. The retailer can then effectively control the wholesale price of the manufacturer through $\alpha$.

Proof. Based on inequality (18) and $4 m \beta-\gamma^{2}>0$, we can obtain the following derivatives:

$$
\begin{aligned}
& \frac{\partial q^{*}}{\partial \alpha} \\
& =\frac{6\left(4 m \beta-\gamma^{2}\right)\left(\sqrt{3} p \mu+3\left(p-2\left(c_{R}+c_{M}+c_{L}\right)\right) \sigma\right) \beta m \sigma}{\left(\alpha \beta m p \sqrt{3}+6 \sigma\left(2 m \alpha+4 m \beta-\gamma^{2}\right)\right)^{2}} \\
& >0 \text {, } \\
& \frac{\partial s^{*}}{\partial \alpha} \\
& =\frac{6\left(4 m \beta-\gamma^{2}\right)\left(\sqrt{3} p \mu+3\left(p-2\left(c_{R}+c_{M}+c_{L}\right)\right) \sigma\right) m \sigma}{\left(\alpha \beta m p \sqrt{3}+6 \sigma\left(2 m \alpha+4 m \beta-\gamma^{2}\right)\right)^{2}} \\
& >0 \text {, } \\
& \frac{\partial x^{*}}{\partial \alpha} \\
& =\frac{3\left(4 m \beta-\gamma^{2}\right)\left(\sqrt{3} p \mu+3\left(p-2\left(c_{R}+c_{M}+c_{L}\right)\right) \sigma\right) \gamma \sigma}{\left(\alpha \beta m p \sqrt{3}+6 \sigma\left(2 m \alpha+4 m \beta-\gamma^{2}\right)\right)^{2}} \\
& >0 \text {, } \\
& \frac{\partial w^{*}}{\partial \alpha} \\
& =-\frac{(\sqrt{3} p \beta+12 \sigma)\left(4 m \beta-\gamma^{2}\right) m}{2\left(\alpha \beta m p \sqrt{3}+6 \sigma\left(2 m \alpha+4 m \beta-\gamma^{2}\right)\right)^{2}} \\
& \cdot\left(\sqrt{3} p \mu+3\left(p-2\left(c_{R}+c_{M}+c_{L}\right)\right) \sigma\right)<0, \\
& \frac{\partial q_{0}{ }^{*}}{\partial \alpha} \\
& =\frac{2\left(4 m \beta-\gamma^{2}\right)^{2}\left(\sqrt{3} p \mu+3\left(p-2\left(c_{R}+c_{M}+c_{L}\right)\right) \sigma\right)}{\left(\alpha \beta m p \sqrt{3}+6 \sigma\left(2 m \alpha+4 m \beta-\gamma^{2}\right)\right)^{2}} \\
& +\alpha c_{M}+\beta c_{L}>0 \text {. }
\end{aligned}
$$

Proposition 4 shows that if the manufacturer increases the unit product's wholesale price, the retailer declines more order quantity. Threatened by the order quantity reduction of the retailer, the manufacturers will reduce the wholesale price. The retailer will then increase the maximum order quantity, which gives the $3 \mathrm{PL}$ a chance to increase the 
logistics service price. The 3PL can increase the logistics service price, which will improve the logistics service level but keep the order quantity steady. The improvement in the logistics service level will also encourage the retailer to provide a higher order quantity. Therefore, the 3PL's logistics service price and level will increase. The increase in the optimal order quantity caused by the reduction in wholesale prices, the improvement of the logistics service level, and the increase in the maximum order quantity can make up for retailer's order quantity reduction caused by the increase in the logistics cost. Therefore, the final order quantity of the retailer also increases. This shows that, with an increase in $\alpha$, when the manufacturer increases the wholesale price, the order quantity of the retailer will decline. In order to refrain the retailer from reducing the order quantity greatly, the manufacturer will reduce the wholesale price. Thus, the retailer can effectively control the wholesale price with $\alpha$ and prevent the manufacturer from raising the price. The increase in the order quantity's sensitivity to the wholesale price also strengthens the retailer's control over the manufacturer. In order to maximize their own profits, the retailer has to increase the maximum order quantity. However, the increase in the maximum order quantity and the decrease in the wholesale price increase the order quantity of the retailer, so the 3PL has room for price increase. That is, the 3PL can improve the partial price but cannot cause a reduction in the order quantity of the retailer, which is most favorable for the 3PL. On one hand, the retailer can receive the benefits of the price increase. On the other hand, it also can receive the benefits of partial order quantity brought by the reduction in wholesale prices. In addition, the improvement of the logistics service level caused by the increase in logistics service price will increase the order quantity of the retailer. Although the increase in the logistics service price of the 3PL would normally reduce the order quantity of the retailer, the improvement of the 3PL's logistics service level and the increase of the maximum order quantity increase the order quantity of the retailer. The combined effect of the manufacturer's and the 3PL's decisions make the final order quantity of the retailer increase.

Proposition 5. With an increase in $\beta$, the logistics service price and level of the 3PL decline, and the wholesale price of the manufacturer and the maximum order quantity increase. If $\alpha>2 \beta$ or $\alpha<2 \beta$ and $m>\gamma^{2} / 2 \alpha$, then the retailer's order quantity increases. If $\alpha<2 \beta$ and $\gamma^{2} / 4 \beta<m<\gamma^{2} / 2 \alpha$, then the retailer's order quantity decreases. Thus, the retailer can effectively control the logistics service price of the 3PL through $\beta$.

Proof. Based on inequality (18) and $4 m \beta-\gamma^{2}>0$, we can obtain the following derivatives:

$$
\begin{aligned}
& \frac{\partial s^{*}}{\partial \beta} \\
& =-\frac{(\sqrt{3} p m \alpha+24 m \sigma)\left(\sqrt{3} p \mu+3\left(p-2\left(c_{R}+c_{M}+c_{L}\right)\right) \sigma\right) m \alpha}{\left(\alpha \beta m p \sqrt{3}+6 \sigma\left(2 m \alpha+4 m \beta-\gamma^{2}\right)\right)^{2}}
\end{aligned}
$$$$
<0,
$$

$$
\begin{aligned}
& \frac{\partial x^{*}}{\partial \beta} \\
& =-\frac{(\sqrt{3} p m \alpha+24 m \sigma)\left(\sqrt{3} p \mu+3\left(p-2\left(c_{R}+c_{M}+c_{L}\right)\right) \sigma\right) \gamma \alpha}{2\left(\alpha \beta m p \sqrt{3}+6 \sigma\left(2 m \alpha+4 m \beta-\gamma^{2}\right)\right)^{2}} \\
& <0, \\
& \frac{\partial w^{*}}{\partial \beta} \\
& =\frac{\left(\gamma^{2} p \sqrt{3}+48 \sigma m \theta_{1}\right) \alpha m\left(\sqrt{3} p \mu+3\left(p-2\left(c_{R}+c_{M}+c_{L}\right)\right) \sigma\right)}{2\left(\alpha \beta m p \sqrt{3}+6 \sigma\left(2 m \alpha+4 m \beta-\gamma^{2}\right)\right)^{2}} \\
& >0, \\
& \frac{\partial q_{0}{ }^{*}}{\partial \beta} \\
& =\frac{\left(\gamma^{2} p \sqrt{3}+48 \sigma m \theta_{1}\right) \alpha^{2} m\left(\sqrt{3} p \mu+3\left(p-2\left(c_{R}+c_{M}+c_{L}\right)\right) \sigma\right)}{2\left(\alpha \beta m p \sqrt{3}+6 \sigma\left(2 m \alpha+4 m \beta-\gamma^{2}\right)\right)^{2}} \\
& \quad+c_{L}>0, \\
& \frac{\partial q^{*}}{\partial \beta}=\frac{6\left(2 m \alpha-\gamma^{2}\right)\left(\sqrt{3} p \mu+3\left(p-2\left(c_{R}+c_{M}+c_{L}\right)\right) \sigma\right) \alpha m \sigma}{\left(\alpha \beta m p \sqrt{3}+6 \sigma\left(2 m \alpha+4 m \beta-\gamma^{2}\right)\right)^{2}} .
\end{aligned}
$$

So, if $2 \alpha m-\gamma^{2}>0$ (i.e., $m>\gamma^{2} / 2 \alpha$ ), then $\partial q^{*} / \partial \beta>0$; if $2 \alpha m-\gamma^{2}<0$ (i.e., $m<\gamma^{2} / 2 \alpha$ ), then $\partial q^{*} / \partial \beta<0$. For $4 \beta m-\gamma^{2}>0$, if $\alpha>2 \beta$, then $m>\gamma^{2} / 4 \beta>\gamma^{2} / 2 \alpha, \partial q^{*} / \partial \beta>$ 0 ; when $\alpha<2 \beta$, if $\gamma^{2} / 4 \beta<m<\gamma^{2} / 2 \alpha$, then $\partial q^{*} / \partial \beta<0$, and if $m>\gamma^{2} / 2 \alpha$, then $\partial q^{*} / \partial \beta>0$.

Proposition 5 shows that if the 3PL increases the unit product's logistics service price, it will decrease more the order quantity of the retailer. Threatened by the retailer's lower order quantity, the 3PL will reduce the logistics service price, and the logistics service level will also decrease. At the same time, the wholesale price of the manufacturer and the maximum order quantity of the retailer will increase. The change in the order quantity is determined by $\beta, \gamma$, and the investment cost. If $\alpha>2 \beta$, i.e., the sensitivity of the order quantity to the wholesale price is twice greater than its sensitivity to the logistics service price, then the order quantity of the retailer increases. When $\alpha<2 \beta$, the change of retailer's order quantity depends on the investment cost. If the investment cost is relatively large (i.e., $m>\gamma^{2} / 2 \alpha$ ), then the order quantity also increases; if the investment cost is relatively small (i.e., $\gamma^{2} / 4 \beta<m<\gamma^{2} / 2 \alpha$ ), then the order quantity will decline. This shows that, with an increase in $\beta$, when the 3PL increases the unit product's logistics service price, the order quantity of the retailer will be further reduced. To prevent large reductions in the retail order quantity, the $3 \mathrm{PL}$ will reduce the logistics service price, and the logistics service level will also decline. Thus, the retailer can effectively control the 3PL's logistics service price with $\beta$ and prevent the 3PL from raising the price, but at the same time, it will reduce the logistics service level. The increase in sensitivity of the order quantity to the wholesale 
price also strengthens the retailer's control over the 3PL. In order to maximize his/her own profits, the retailer has to increase the maximum order quantity. However, the increase in the maximum order quantity and the decrease in the 3PL's logistics service price give the manufacturer a chance to increase the wholesale price. The manufacturer can increase the partial price without causing a reduction in the order quantity, which is the most favorable for the manufacturer. On one hand, the manufacturer can benefit from the price increase. On the other hand, it can benefit from the increase in the partial order quantity brought by the reduction of the logistics service price and the improvement in the logistics service level. Although the increase in the wholesale price and the decrease in the logistics service level would normally reduce the retailer's order quantity, the reduction in the logistics service price and the increase in the maximum order quantity increase the order quantity. Finally, their combined effect leads to an increase in the retailer's order quantity. When the sensitivity of the order quantity to the wholesale price is twice greater than the sensitivity of the order quantity to the logistics service price, the retailer's control over the logistics service price is relatively small. With an increase in $\beta$ to increase the order quantity, the logistics service price will decrease greatly. The increase in the order quantity caused by the reduction in the logistics service price and the increase in the maximum order quantity can make up for its reduction caused by the increase in the wholesale price and the decrease in the logistics service level. Therefore, the final order quantity of the retailer also increases. When the sensitivity of the order quantity to the wholesale price is twice smaller than the sensitivity of the order quantity to the logistics service price, i.e., $\alpha<2 \beta$, then with an increase in $\beta$ to increase the order quantity, the logistics service price will decrease slightly. If the investment cost is relatively high, i.e., $m>\gamma^{2} / 2 \alpha$, the cost of improving logistics service level will be high; thus the 3PL will decrease logistics service level greatly, which will lead to a great decrease of the logistics service price. The combination of the manufacturer and the 3PL's decisions will make the final order quantity of the retailer increase. If the investment cost is relatively low, i.e. $\gamma^{2} / 4 \beta<$ $m<\gamma^{2} / 2 \alpha$, thus the 3PL will decrease logistics service level slightly, which will lead to slight decrease of logistics service price. The combination of the manufacturer and the 3PL's decisions will then cause the final order quantity of the retailer to decline.

Proposition 6. With an increase in $\sigma$, the maximum order quantity, the optimal order quantity, the wholesale price, and the logistics service price and level will increase or decrease at the same time.

Proof. If we suppose that $G_{1}=\left(\left(\left(p-2 c_{R}-2 c_{M}-2 c_{L}\right) \beta-\right.\right.$ $4 \mu) \alpha-8 \mu \beta) m+2 \mu \gamma^{2}$, based on $4 m \beta-\gamma^{2}>0$, we can obtain the following derivatives:

$$
\frac{\partial q_{0}{ }^{*}}{\partial \sigma}=\frac{3\left(4 \beta m-\gamma^{2}\right) G_{1}}{\left(\alpha \beta m p \sqrt{3}+6 \sigma\left(2 m \alpha+4 m \beta-\gamma^{2}\right)\right)^{2}},
$$

$$
\begin{aligned}
& \frac{\partial q^{*}}{\partial \sigma}=\frac{3 \sqrt{3} m \alpha \beta p G_{1}}{\left(\alpha \beta m p \sqrt{3}+6 \sigma\left(2 m \alpha+4 m \beta-\gamma^{2}\right)\right)^{2}}, \\
& \frac{\partial s^{*}}{\partial \sigma}=\frac{3 \sqrt{3} m \alpha p G_{1}}{\left(\alpha \beta m p \sqrt{3}+6 \sigma\left(2 m \alpha+4 m \beta-\gamma^{2}\right)\right)^{2}}, \\
& \frac{\partial x^{*}}{\partial \sigma}=\frac{3 \sqrt{3} \gamma \alpha p G_{1}}{2\left(\alpha \beta m p \sqrt{3}+6 \sigma\left(2 m \alpha+4 m \beta-\gamma^{2}\right)\right)^{2}}, \\
& \frac{\partial w^{*}}{\partial \sigma}=\frac{3 \sqrt{3} p\left(4 \beta m-\gamma^{2}\right) G_{1}}{2\left(\alpha \beta m p \sqrt{3}+6 \sigma\left(2 m \alpha+4 m \beta-\gamma^{2}\right)\right)^{2}} .
\end{aligned}
$$

If $G_{1}>0$, i.e., $\mu>\left(p-2 c_{R}-2 c_{M}-2 c_{L}\right) \beta \alpha m /(2 \alpha m+2(4 \beta m-$ $\left.\left.\gamma^{2}\right)\right)$, then $\partial q_{0}^{*} / \partial \sigma<0, \partial w^{*} / \partial \sigma<0, \partial s^{*} / \partial \sigma<0, \partial q^{*} / \partial \sigma<0$; if $G_{1}<0$, i.e., $\mu<\left(p-2 c_{R}-2 c_{M}-2 c_{L}\right) \beta \alpha m /(2 \alpha m+2(4 \beta m-$ $\left.\left.\gamma^{2}\right)\right)$, then $\partial q_{0}^{*} / \partial \sigma>0, \partial w^{*} / \partial \sigma>0, \partial s^{*} / \partial \sigma>0, \partial q^{*} / \partial \sigma>$ 0 .

Proposition 6 shows that the supply chain members move in the same direction as the market demand fluctuates. That is, no matter how the market fluctuates, the maximum order quantity, the optimal order quantity, the wholesale price, and the logistics service price and level will increase or decrease at the same time.

When $p<2\left(c_{R}+c_{M}+c_{L}\right)$, i.e., the retail price is two times less than the variable total cost of the system, the selling price is relatively low. Because $\mu>0$, then $\mu>$ $\left(p-2 c_{R}-2 c_{M}-2 c_{L}\right) \beta \alpha m /\left(2 \alpha m+2\left(4 \beta m-\gamma^{2}\right)\right) . \mu$ is the average rate of the market demand, and it is positive. At this point, although the average market demand is higher, the unit product's profit for the retailer is lower. With an increase in the market volatility, the retailer's selling risk will increase; thus the lower profits will reduce the maximum order quantity of the retailer. In order to refrain the retailer from reducing the order quantity greatly, the manufacturer and the 3PL will reduce their prices. The logistics service level is also reduced. Although the 3PL and the manufacturers reduce prices to keep the order quantity, the final order of the retailer will be reduced due to the reduction of the logistics service level and the maximum order quantity.

When $p>2\left(c_{R}+c_{M}+c_{L}\right)$, i.e., the retail price is two times the total cost of the system, the sales price is relatively high. The maximum order quantity, the optimal order quantity, the wholesale price, and the logistics service price and level will increase or decrease simultaneously, which depends on the average market demand.

If $\mu>\left(p-2 c_{R}-2 c_{M}-2 c_{L}\right) \beta \alpha m /\left(2 \alpha m+2\left(4 \beta m-\gamma^{2}\right)\right)$, the average market demand is relatively large, and the retailer's profit is relatively high. The increase in the market volatility increases the retailer's sales risk, even though the higher unit product's profit still cannot offset the loss caused by the sales risk, so the retailer will still reduce the maximum order quantity. In the same way, the 3PL and the manufacturer will reduce their prices, and the 3PL's logistics service level and the retailer's final order quantity will also decline. 
TABLE 1: The effect of the logistics investment cost on the supply chain members' decisions.

\begin{tabular}{|c|c|c|c|c|c|}
\hline $\begin{array}{l}\text { Logistics } \\
\text { investment cost }\end{array}$ & $\begin{array}{c}\text { Maximum order } \\
\text { quantity }\end{array}$ & Service price & Service level & $\begin{array}{c}\text { Wholesale } \\
\text { price }\end{array}$ & $\begin{array}{c}\text { Optimal order } \\
\text { quantity }\end{array}$ \\
\hline 25.00 & $1,212.00$ & 4.04 & 2.04 & 7.06 & 204.00 \\
\hline 30.00 & $1,241.72$ & 4.03 & 1.69 & 7.21 & 202.65 \\
\hline 35.00 & $1,262.71$ & 4.02 & 1.44 & 7.31 & 201.69 \\
\hline 40.00 & $1,278.32$ & 4.01 & 1.26 & 7.39 & 200.98 \\
\hline 45.00 & $1,290.39$ & 4.00 & 1.11 & 7.45 & 200.44 \\
\hline 50.00 & $1,300.00$ & 4.00 & 1.00 & 7.50 & 200.00 \\
\hline
\end{tabular}

If $\mu<\left(p-2 c_{R}-2 c_{M}-2 c_{L}\right) \beta \alpha m /\left(2 \alpha m+2\left(4 \beta m-\gamma^{2}\right)\right)$, the average market demand is relatively small, but the retailer's profit is relatively high. In this situation, relative to the original smaller market demand, the increase in the market volatility will give the retailer an opportunity to sell more products. Because the original market demand is already very small, there is less room for market demand reduction and more room for market demand to increase. Therefore, relative to the loss caused by the decrease of demand, the increase of demand will bring more profits to the retailer. Finally, the retailer will raise the maximum order quantity. At this time, the manufacturer and the 3PL do not need to reduce their prices to maintain the retailer' order quantity. In order to maximize their own profits, the manufacturer and the 3PL will increase their own prices, but they will not reduce the final order quantity below the original quantity, so the 3PL's logistics service level and the final order quantity of the retailer also increase.

In summary, the risk appetite of the supply chain members depends on the retailer's unit product's profit level and the size of the market demand. It is not dependent on the logistics service investment cost. When the retailer's unit product's profit is lower (that is, the selling price is lower than twice of the system cost) or the retailer's unit product's profit is higher (that is, the selling price is higher than twice of the system cost) and the market demand is higher, the retailer's order quantity, the wholesale price of the manufacturer, the logistics service price, and the service level of the 3PL decrease. However, only when the retailer's unit product's profit is higher (that is, the selling price is higher than twice the system cost) and the market demand is higher do all the decisions increase.

\section{Numerical Illustration}

In the logistics outsourcing business, the logistics service investment cost $m$ and the sensitivity coefficient $\gamma$ of the order quantity to the logistics service level have a great influence on the 3PL's decision. At the same time, the sensitivity coefficient $\alpha$ of the order quantity to the wholesale price, the sensitivity coefficient $\beta$ of the order quantity to the logistics service price, and the market risk $\sigma$ are particularly important for the profit of the supply chain members. To further illustrate the impact of $m, \gamma, \alpha, \beta$, and $\sigma$ on the decisions and profit of supply chain members, this section provides a numerical example.

The parameters are given as $c_{M}=4, c_{L}=2, c_{R}=3, p=$ 40, $\alpha=100, \beta=100$, and $m=25$. The market demand

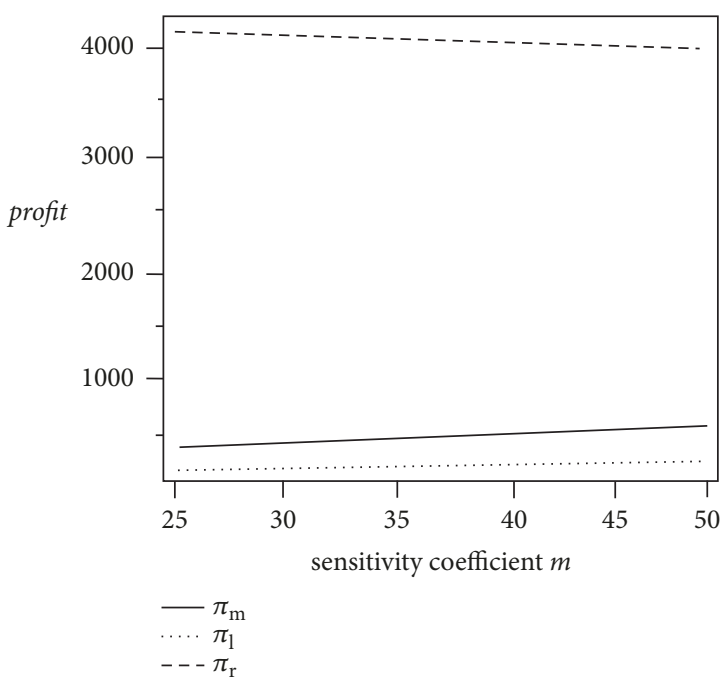

FIGURE 2: The effect of the logistics investment cost on the supply chain members' profits.

meets the uniform distribution of $[100,300]$, so $I_{1}=100$, $I_{2}=300, \mu=\left(I_{1}+I_{2}\right) / 2=200$, and $\sigma=\sqrt{\left(I_{2}-I_{1}\right)^{2} / 12}=$ $100 \sqrt{3} / 3$. Given that the other parameters are constant, we investigate changes in the decisions and profits of the supply chain members when $m, \gamma, \alpha, \beta$, and $\sigma$ change, respectively. Because the effects of the parameters above on the decisions of the supply chain members have been analyzed in the previous part, the discrete point set form-tables are used to represent the decision changes of the supply chain members. To better illustrate the effects of the parameter changes on the supply chain members' equilibrium profits, continuous graphic form-figures are used.

5.1. Changes in Equilibrium Decisions and Profits with the Sensitivity Coefficient $m$. With all other parameters held equal, we first investigate how the equilibrium decisions and profit of all supply chain members respond to changes in the investment cost coefficient of logistics service. Table 1 indicates that when the investment cost coefficient increases, the logistics service price and level of the 3PL decrease. The order quantity of the retailer also decreases the wholesale price of the manufacturer and the maximum order quantity of the retailer increases. All these results are in line with Proposition 2. As shown in Figure 2, when $m$ increases, the 
TABLE 2: The effect of the sensitivity coefficient of the order quantity to the logistics service level on the supply chain members' decisions.

\begin{tabular}{lccccc}
\hline $\begin{array}{l}\text { Sensitivity coefficient of order quantity to } \\
\text { logistics service level }\end{array}$ & $\begin{array}{c}\text { Maximum order } \\
\text { quantity }\end{array}$ & Service price & Service level & $\begin{array}{c}\text { Wholesale } \\
\text { price }\end{array}$ & $\begin{array}{c}\text { Optimal order } \\
\text { quantity }\end{array}$ \\
\hline 50.00 & $1,212.00$ & 4.04 & 2.04 & 7.06 & 204.00 \\
55.00 & $1,173.98$ & 4.06 & 2.26 & 6.87 & 205.73 \\
60.00 & $1,131.60$ & 4.08 & 2.49 & 6.66 & 207.65 \\
65.00 & $1,084.62$ & 4.10 & 2.73 & 6.42 & 209.79 \\
70.00 & $1,032.78$ & 4.12 & 2.97 & 6.16 & 212.15 \\
75.00 & 975.79 & 4.15 & 3.22 & 5.88 & 214.74 \\
\hline
\end{tabular}

retailer's profit decreases while the 3PL's and the manufacturer's profits both increase. This is because although the reduction in the logistics service price and the order quantity decreases profit of 3PL, the profit increased by the reduction of the logistics investment cost compensates for the profit loss caused by the reduction of the logistics service price and the order quantity. Therefore, the 3PL's final profit increases.

The increase in the wholesale price causes the manufacturer's profit to increase while the decrease in the order quantity causes the manufacturer's profit to decrease. By increasing the wholesale price, the increase in the manufacturer's profit can compensate for the loss of profit caused by the reduction in the order quantity. Thus, the final profit of the manufacturer also increases. For the retailer, although the reduction in the logistics service price reduces his/her cost, the increase in the wholesale price increases his/her cost burden and the decrease in the order quantity decreases the profit. Since the profit increase brought by the decrease of the logistics service price cannot compensate for the loss caused by the increase of the wholesale price and the decrease of the order quantity, the final profit of the retailer decreases.

5.2. Changes in Equilibrium Decisions and Profit with the Sensitivity Coefficient $\gamma$. Again, assuming that all other parameters hold equal, we examine how the equilibrium decisions and profits of all supply chain members respond to a change in the sensitivity coefficient $\gamma$. As we can see in Table 2, when the sensitivity coefficient $\gamma$ increases, the logistics service price, the logistics service level of the 3PL, and the retailer's order quantity increase while the wholesale price of the manufacturer and the maximum order quantity decline. All these results are in line with Proposition 3. As can be seen in Figure 3, with an increase in the sensitivity coefficient $\gamma$, the retailer's profit increases while the 3PL's and the manufacturer's profits decrease. This is because the increased profit brought by the rise of the logistics service price and the order quantity cannot make up for the loss in profits caused by the increase in the logistics service level. Therefore, the 3PL's final profit decreases. For the manufacturer, the increased profit brought by the increase in wholesale price cannot make up for the loss of profit caused by the decreased order quantity. Therefore, the manufacturer's final profit also decreases. For the retailer, although the increased logistics service price raises his/her cost burden, the decreased wholesale price and the increased order quantity

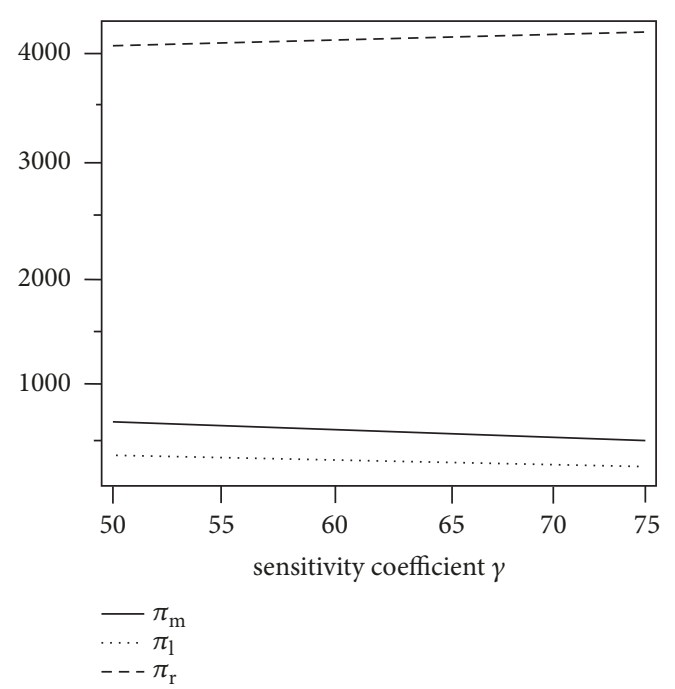

FIGURE 3: The effect of the sensitivity coefficient of the order quantity to the logistics service level on the supply chain members' profit.

raise his/her profit. The profit brought by the decreased wholesale price and the increased order quantity make up for the loss caused by the increased logistics service price. Thus, the retailer's final profit increases.

5.3. Changes in Equilibrium Decisions and Profits with the Sensitivity Coefficient $\alpha$. Holding other parameters equal, we now examine how the equilibrium decisions and profit of all supply chain members respond to changes in the sensitivity coefficient $\alpha$. As we can see in Table 3, when the sensitivity coefficient $\alpha$ increases, the wholesale price of the manufacturer decreases, and the 3PL's logistics service price and level, the retailer's maximum order quantity, and order quantity increase. All these results are in line with Proposition 4. Furthermore, as we can see in Figure 4, when the sensitivity coefficient $\alpha$ increases, the manufacturer's profit decreases while the profits of the 3PL and the retailer increase. Table 3 shows that an increase in the sensitivity coefficient $\alpha$ leads the logistics service price of the 3PL to increase and the wholesale price of the manufacturer to decrease. However, the increased value of the logistics service price is smaller than the decreased value of the wholesale price. For example, when $\alpha$ increases from 100 
TABLE 3: The effect of the sensitivity coefficient of the order quantity to the wholesale price on the supply chain members' decisions.

\begin{tabular}{|c|c|c|c|c|c|}
\hline $\begin{array}{l}\text { Sensitivity coefficient of order quantity to } \\
\text { wholesale price }\end{array}$ & $\begin{array}{l}\text { Maximum order } \\
\text { quantity }\end{array}$ & Service price & Service level & $\begin{array}{c}\text { Wholesale } \\
\text { price }\end{array}$ & $\begin{array}{c}\text { Optimal order } \\
\text { quantity }\end{array}$ \\
\hline 100.00 & $1,212.00$ & 4.04 & 2.04 & 7.06 & 204.00 \\
\hline 110.00 & $1,258.75$ & 4.06 & 2.06 & 6.81 & 206.25 \\
\hline 120.00 & $1,304.49$ & 4.08 & 2.08 & 6.60 & 208.16 \\
\hline 130.00 & $1,349.43$ & 4.10 & 2.10 & 6.42 & 209.81 \\
\hline 140.00 & $1,393.73$ & 4.11 & 2.11 & 6.26 & 211.24 \\
\hline 150.00 & $1,437.50$ & 4.12 & 2.12 & 6.12 & 212.50 \\
\hline
\end{tabular}

TABLE 4: The effect of the sensitivity coefficient of the order quantity to the logistics service price on the supply chain members' decisions.

\begin{tabular}{lccccc}
\hline $\begin{array}{l}\text { Sensitivity coefficient of the order quantity to } \\
\text { the service price }\end{array}$ & $\begin{array}{c}\text { Maximum order } \\
\text { quantity }\end{array}$ & Service price & Service level & $\begin{array}{c}\text { Wholesale } \\
\text { price }\end{array}$ & $\begin{array}{c}\text { Optimal order } \\
\text { quantity }\end{array}$ \\
\hline 100.00 & $1,212.00$ & 4.04 & 2.04 & 7.06 & 204.00 \\
110.00 & $1,252.85$ & 3.86 & 1.86 & 7.16 & 204.74 \\
120.00 & $1,290.34$ & 3.71 & 1.71 & 7.25 & 205.37 \\
130.00 & $1,325.22$ & 3.58 & 1.58 & 7.33 & 7.39 \\
140.00 & $1,358.03$ & 3.47 & 1.47 & 205.90 \\
150.00 & $1,389.19$ & 3.38 & 1.38 & 7.45 & 206.36 \\
\hline
\end{tabular}

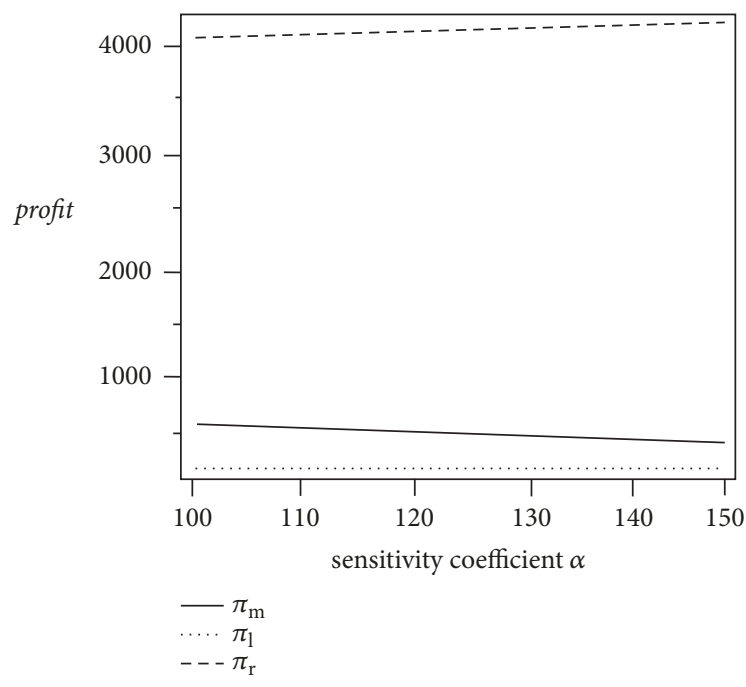

FIGURE 4: The effect of the sensitivity coefficient of the order quantity to the wholesale price on the supply chain members' profits.

to 110 , the manufacturer's wholesale price decreases by 7.06 $6.81=0.25$, while the logistics service price increases by 4.06 $4.04=0.02$. Therefore, the retailer's purchase cost declines, more importantly, the order quantity also increases, and the profit of the retailer rises. For the manufacturer, the profit brought by the increased order quantity is not enough to compensate for the loss caused by the decreased wholesale price; thus the profit of the manufacturer declines.

For the 3PL, the profit brought by the increased order quantity and logistics service price is enough to compensate for the loss caused by the increased logistics service level, which means that the profit of the 3PL increases. The retailer can therefore effectively prevent manufacturers from raising price by increasing the value of $\alpha$ and increasing their own profit. This constraint on the manufacturer is conducive to improving the profit of the 3PL.

5.4. Changes in Equilibrium Decisions and Profit in Relation to the Sensitivity Coefficient $\beta$. Again, holding other parameters equal, we investigate how the equilibrium decisions and profit of all supply chain members respond to changes in the sensitivity coefficient $\beta$. According to our hypothesis above, when the sensitivity coefficient $\beta$ increases from 100 to 150 , it will always meet the conditions $\alpha<2 \beta$ and $m=$ $25>\gamma^{2} / 2 \alpha=25 / 2$. According to Proposition 5, when the sensitivity coefficient $\beta$ increases, the logistics service price and level of the 3PL decrease while the manufacturer's wholesale price and the retailer's order quantity increase. This theoretical result is supported by our numerical illustration in Table 4. In Figure 5, we can further observe that, with an increase in the sensitivity coefficient $\beta$, the profits of the retailer and the manufacturer increase while the profit of the 3PL decreases. This happens because for the manufacturer, the increased order quantity and decreased wholesale price both cause his/her profit to increase. Thus, the manufacturer's profit increases. For the retailer, the profit brought by the increased order quantity and the decreased logistics service price can offset the loss caused by the increased wholesale price, which finally leads to an increase in profit for the retailer. For the 3PL, the profit brought by the increased order quantity and the decreased logistics service level cannot offset the loss caused by the decreased logistics service price; thus the profit of the $3 \mathrm{PL}$ declines. This shows that the retailer can effectively push the 3PL to reduce his/her prices by raising the value of $\beta$. 
TABLE 5: The effect of the market risk parameter on the supply chain members' decisions.

\begin{tabular}{|c|c|c|c|c|c|}
\hline Risk & $\begin{array}{c}\text { Maximum order } \\
\text { quantity }\end{array}$ & Service price & Service level & $\begin{array}{l}\text { Wholesale } \\
\text { price }\end{array}$ & $\begin{array}{c}\text { Optimal order } \\
\text { quantity }\end{array}$ \\
\hline $100 / \sqrt{3}$ & $1,212.00$ & 4.04 & 2.04 & 7.06 & 204.00 \\
\hline $120 / \sqrt{3}$ & $1,213.85$ & 4.05 & 2.05 & 7.07 & 204.62 \\
\hline $140 / \sqrt{3}$ & $1,215.56$ & 4.05 & 2.05 & 7.08 & 205.18 \\
\hline $160 / \sqrt{3}$ & $1,217.14$ & 4.06 & 2.06 & 7.09 & 205.71 \\
\hline $180 / \sqrt{3}$ & $1,218.62$ & 4.06 & 2.06 & 7.09 & 206.21 \\
\hline $200 / \sqrt{3}$ & $1,220.00$ & 4.07 & 2.07 & 7.10 & 206.67 \\
\hline
\end{tabular}

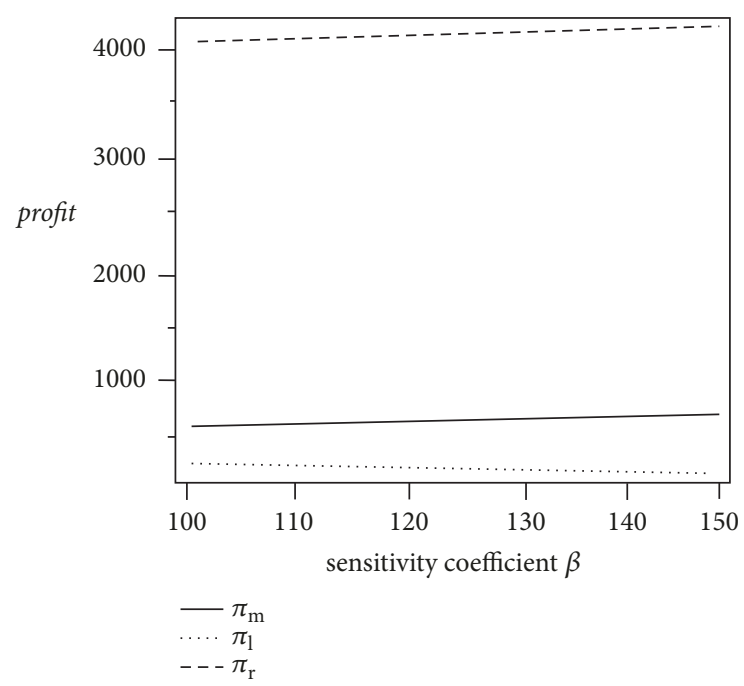

FIGURE 5: The effect of the sensitivity coefficient of the order quantity to the logistics service price on the supply chain members' profits.

\subsection{Changes in Equilibrium Decisions and Profits in Relation} to the Market Risk $\sigma$. Holding other parameters equal, we finally examine how the equilibrium decisions and profit of all supply chain members respond to changes in the market risk $\sigma$. The larger the value of $\sigma$, the greater the demand volatility and the risk. As shown in Table 5, when $\sigma$ increases, the maximum order quantity, the optimal order quantity, the wholesale price of the manufacturer, the logistics service price, and service level of the 3PL all increase. These results are fully in line with Proposition 6. This shows that when the market risk increases, all supply chain members tend to be risk seeker when making decisions. Figure 6 graphically shows that when the market risk increases, the profit of the retailer decreases while the profits of the 3PL and the manufacturer increase. This is due to the following reason: for the 3PL, although the increased logistics service level increases the logistics investment cost, the profit brought by the increased logistics service price and order quantity can compensate for the loss caused by the increased logistics service level. Therefore, the profit of the 3PL increases. For the manufacturer, the increased wholesale price and order quantity cause the manufacturer's final profit to increase. For the retailer, profit increased by the raising quantity cannot offset the loss caused by the increased wholesale price and

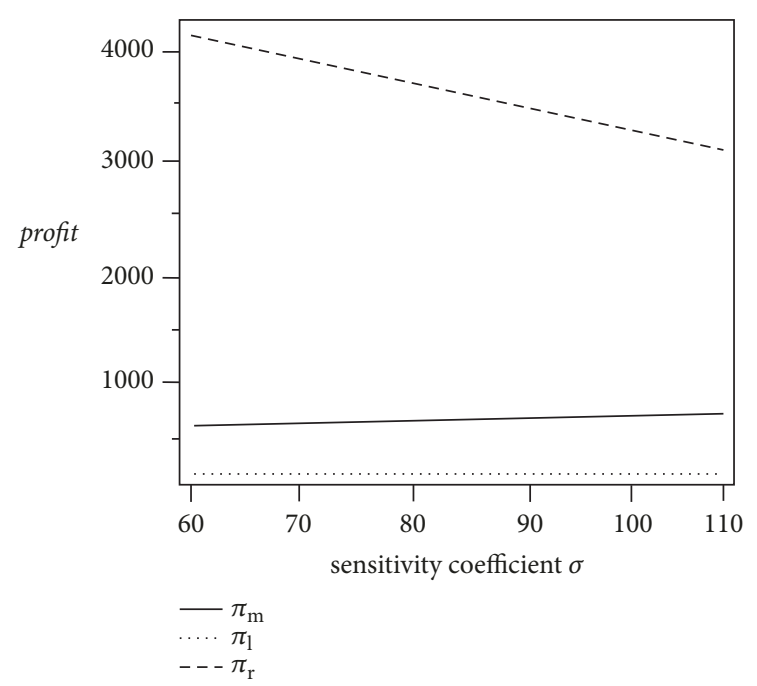

FIGURE 6: The effect of the market risk parameter on the supply chain members' profits.

logistics service price. Thus, the retailer's profits will decline in the end.

\section{Conclusions}

In this paper, we introduce the logistics service level into a supply chain decision model to determine its stochastic demand in a system with a dominant retailer. Using game theory, we obtain the optimal equilibrium decisions of the manufacturer, the 3PL, and the retailer. In addition, we examine the effect of various sensitivity coefficients on the equilibrium decisions of all supply chain members.

Extant research has shown that a lower investment cost coefficient aimed at improving the logistics service level or a higher sensitivity of the order quantity to the logistics service level will effectively improve it and increase the profit of the retailer. Moreover, the retailer can effectively reduce the 3PL's and the manufacturer's prices by adjusting the sensitivity coefficient. The risk preference of the supply chain members depends not only on the retailer's pricing, but also on the market demand. Due to the retailer's dominant position, his/her profit is always greater than that of other supply chain members. 
In practice, the concentration of the retail industry continues to improve as more and more retail companies become dominant in the supply chain. Simultaneously, a large number of professional third-party logistics companies (3PL) are rapidly developing with the increasing consumer demands on the logistics service level. There are many cases of logistics outsourcing in the retail industry. The research findings of this paper provide decision-making advice for retailers, manufacturers, and 3PL in a scenario with dominant retailer and logistics outsourcing. At the same time, these research findings also provide a basis for these companies to respond to market changes and forecast market trends and answer some of the questions they might have. For example, for the 3PL, under what conditions is it beneficial to invest in improving logistics service level and should it be invested in? For the retailer, how can one use his/her dominant position to reduce the logistics price and the wholesale price, promote 3PL to improve the logistics level, and increase the final profit? For the manufacturer, how should the optimal wholesale price be set according to the retailer's ordering strategy to maximize profits? For all supply chain members, how should their decision-making processes be adjusted to increase their profits when the market changes? All these answers can be obtained from the research findings of this paper.

The conclusions drawn in this paper are based on symmetric information, and we assume that most of the information is private. In future research, it would be interesting to explore the supply chain members' decision-making under asymmetric information that considers the logistics service level in this area. Furthermore, we have assumed a uniform distribution of the market demand, even though the distribution of the market demand is likely nonuniform in reality. Thus, another venue for future research could be the decision of the supply chain members under a different market demand distribution of the logistics service level so that it is more realistic and provides a better theoretical basis for practical applications of supply chain management.

\section{Data Availability}

The data used to support the findings of this manuscript are included within the Supplementary Materials.

\section{Conflicts of Interest}

The authors declare that there are no conflicts of interest regarding the publication of this paper.

\section{Acknowledgments}

This work was supported by the National Social Science Foundation of China (no. 16BGL002), the Youth Foundation of Humanities and Social Sciences of Ministry of Education of China (no. 14YJC630152), and the China Postdoctoral Science Foundation (no. 2014M562504XB).

\section{Supplementary Materials}

The supplementary material of our manuscript, as a supplement to the numerical illustration part, describes the source of parameter data, which comes from the field survey of 30 companies in Hebei Province in China. According to the results of the survey, the parameters in the paper are assigned. The supplementary material also describes the process of obtaining the results of decision variables and the formation process of Figures 2-6 and explains the reasons why decision variables vary with relevant parameters. (Supplementary Materials)

\section{References}

[1] S. H. Hum, "A Hayes-wheelwright framework approach for strategic management of third party logistics services," Integrated Manufacturing Systems, vol. 11, no. 2, pp. 132-137, 2000.

[2] H. Baligil, S. S. Kara, P. Alcan, B. Özkan, and E. Gözde Alar, "A distribution network optimization problem for third party logistics service providers," Expert Systems with Applications, vol. 38, no. 10, pp. 12730-12738, 2011.

[3] T. B. Gooley, "Selling logistics," Logistics Management, vol. 35, no. 11, pp. 44-47, 1996.

[4] L. A. Crosby, K. R. Evans, and D. Cowles, "Relationship quality in services selling: an interpersonal influence perspective," Journal of Marketing, vol. 54, no. 3, pp. 68-81, 1990.

[5] E. W. Anderson, C. Fornell, and D. R. Lehmann, "Customer satisfaction, market share, and profitability: findings from Sweden," Journal of Marketing, vol. 58, no. 3, pp. 53-66, 1994.

[6] J. Raju and Z. J. Zhang, "Channel coordination in the presence of a dominant retailer," Marketing Science, vol. 24, no. 2, pp. 254262, 2005.

[7] Z. Hua and S. Li, "Impacts of demand uncertainty on retailer's dominance and manufacturer-retailer supply chain cooperation," Omega-International Journal of Management Science, vol. 36, no. 5, pp. 697-714, 2008.

[8] L. Jiang, Y. Wang, and D. Liu, "Logistics cost sharing in supply chains involving a third-party logistics provider," Central European Journal of Operations Research, vol. 24, no. 1, pp. 207230, 2016.

[9] L. Lei, Q. Wang, and C. Fan, "Optimal business policies for a supplier-transporter-buyer channel with a price-sensitive demand," Journal of the Operational Research Society, vol. 57, no. 3, pp. 281-289, 2006.

[10] H. S. Woo and S. Saghiri, "Order assignment considering buyer, third-party logistics provider, and suppliers," International Journal of Production Economics, vol. 130, no. 2, pp. 144-152, 2011.

[11] L. Li, Y. Wang, and W. Dai, "Coordinating a supply chain with transport service providers," Journal of Industrial and Production Engineering, vol. 30, no. 2, pp. 105-116, 2013.

[12] L. Li, Y. Wang, and W. Dai, "Coordinating supplier retailer and carrier with price discount policy," Applied Mathematical Modelling: Simulation and Computation for Engineering and Environmental Systems, vol. 40, no. 1, pp. 646-657, 2016.

[13] X.-F. Chen and X. Xie, "The value of integrated logistics and finance services of third party logistics firms," International Journal of Services Operations and Informatics, vol. 4, no. 4, pp. 333-351, 2009. 
[14] X. Chen and G. Cai, "Joint logistics and financial services by a 3PL firm," European Journal of Operational Research, vol. 214, no. 3, pp. 579-587, 2011.

[15] L. Jiang, Y. Wang, and X. Yan, "Decision and coordination in a competing retail channel involving a third-party logistics provider," Computers \& Industrial Engineering, vol. 76, no. 1, pp. 109-121, 2014.

[16] W. S. Lim, "Lemons market? an incentive scheme to induce truth-telling in third party logistics providers," European Journal of Operational Research, vol. 125, no. 3, pp. 519-525, 2000.

[17] Q. Wu, Y. Mu, and Y. Feng, "Coordinating contracts for fresh product outsourcing logistics channels with power structures," International Journal of Production Economics, vol. 160, no. 2, pp. 94-105, 2015.

[18] X. Cai, J. Chen, Y. Xiao, X. Xu, and G. Yu, "Fresh-product supply chain management with logistics outsourcing," OMEGA - The International Journal of Management Science, vol. 41, no. 4, pp. 752-765, 2013.

[19] K. Chen and T. Xiao, "Demand disruption and coordination of the supply chain with a dominant retailer," European Journal of Operational Research, vol. 197, no. 1, pp. 225-234, 2009.

[20] T. Choi, Y. Li, and L. Xu, "Channel leadership, performance and coordination in closed loop supply chains," International Journal of Production Economics, vol. 146, no. 1, pp. 371-380, 2013.

[21] J. Zhao, J. Wei, and Y. Li, "Pricing decisions for substitutable products in a two-echelon supply chain with firms' different channel powers," International Journal of Production Economics, vol. 153, no. 7, pp. 243-252, 2014.

[22] K. Pan, K. K. Lai, L. Liang, and S. C. H. Leung, “Two-period pricing and ordering policy for the dominant retailer in a two-echelon supply chain with demand uncertainty," OmegaInternational Journal of Management Science, vol. 37, no. 4, pp. 919-929, 2009.

[23] B. Y. Hu, Y. Feng, and X. Chen, "Optimization and coordination of supply chains under the retailers profit margin constraint," Computers \& Industrial Engineering, vol. 126, no. 1, pp. 569-577, 2018.

[24] T. Tsuboi, T. Nishi, and G. Zhang, "Analysis of leadership structures for two-echelon supply chains involving multiple risky suppliers," Journal of Advanced Mechanical Design, Systems, and Manufacturing, vol. 12, no. 3, pp. 1-14, 2018.

[25] P. W. Dobson, R. C. Stephen, and D. M. Waterson, "Buyer power and its impact on competition in the food retail distribution sector of the European union," Journal of Industry, Competition and Trade, vol. 1, no. 3, pp. 247-281, 2001.

[26] A. I. El-Ansary and L. W. Stern, "Power measurement in the distribution channel," Journal of Marketing Research, vol. 9, no. 1, pp. 47-52, 1972.

[27] S. D. Hunt and J. R. Nevin, "Power in a channel of distribution: sources and consequences," Journal of Marketing Research, vol. 11, no. 2, pp. 186-193, 1974.

[28] X. Han, X. Sun, and Y. Zhou, "The equilibrium decisions in a two-echelon supply chain under price and service competition," Sustainability, vol. 6, no. 7, pp. 4339-4354, 2014. 


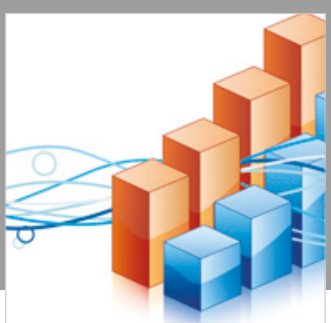

Advances in

Operations Research

\section{-n-m}
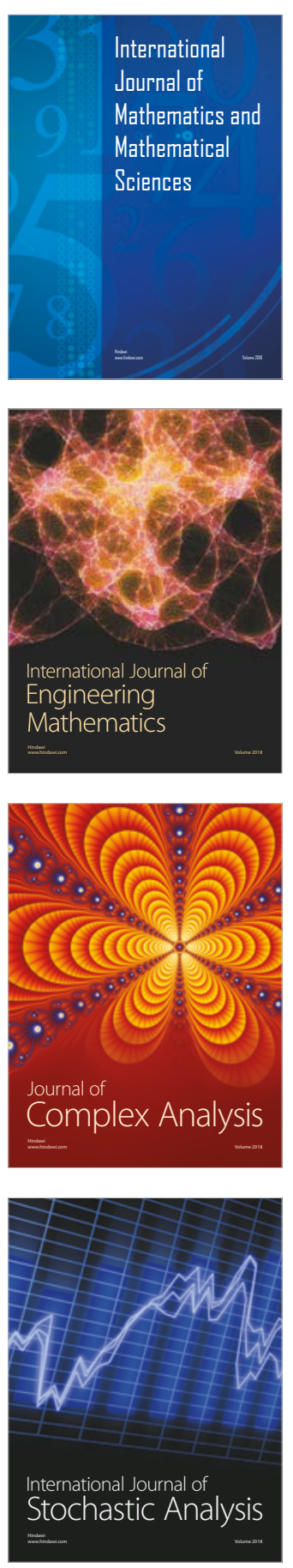
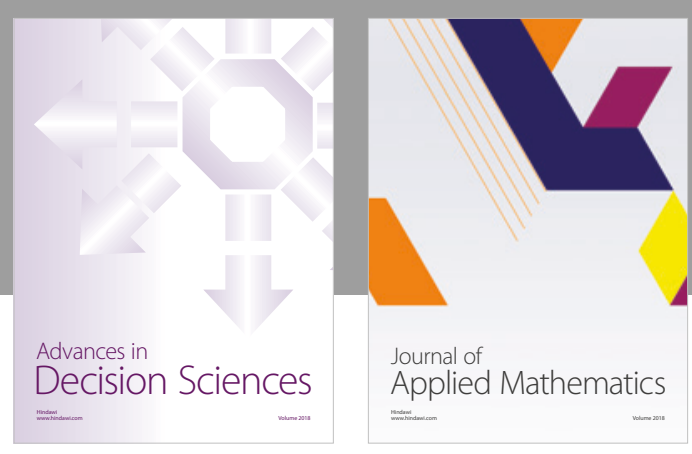

Journal of

Applied Mathematics
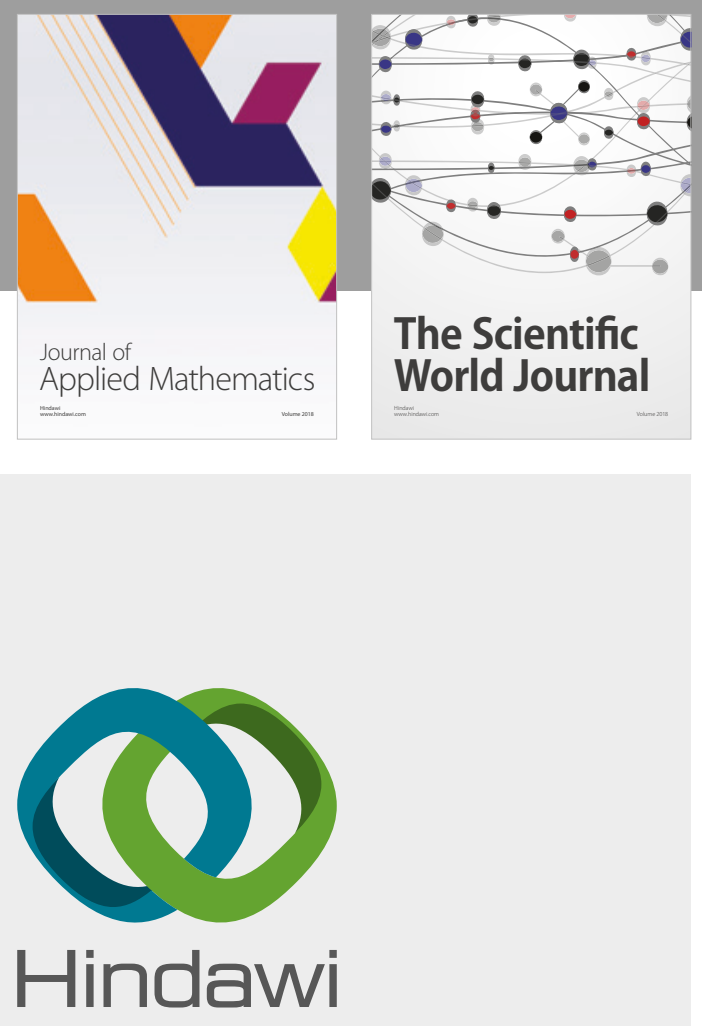

Submit your manuscripts at

www.hindawi.com

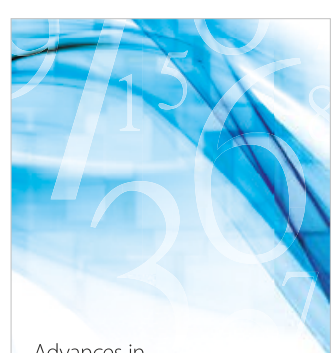

Advances in
Numerical Analysis
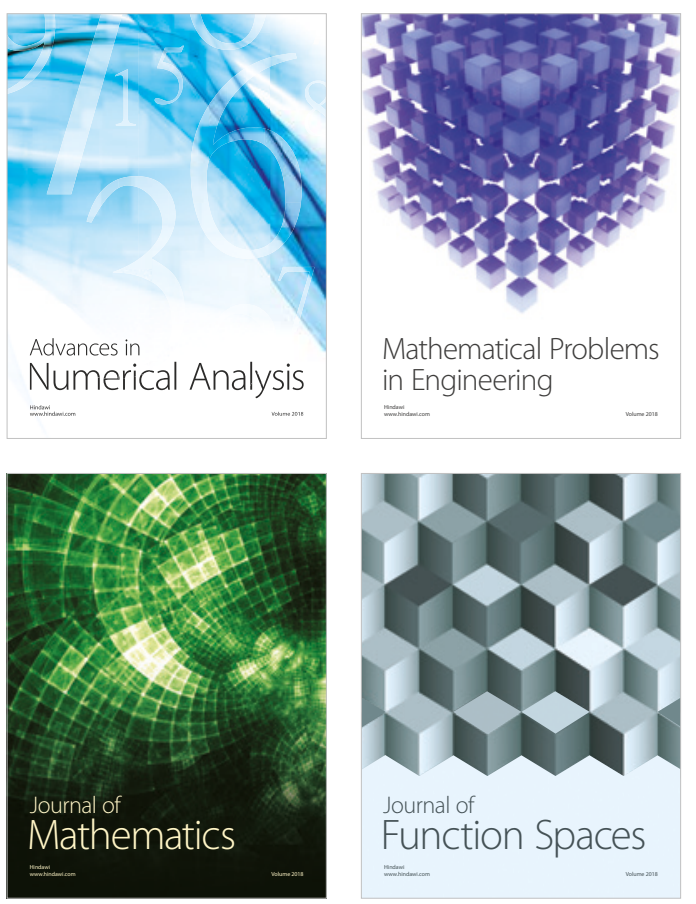

Mathematical Problems in Engineering

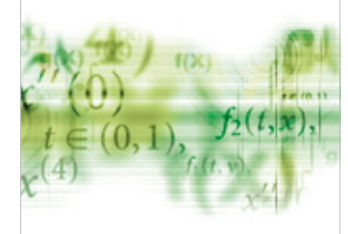

International Journal of

Differential Equations

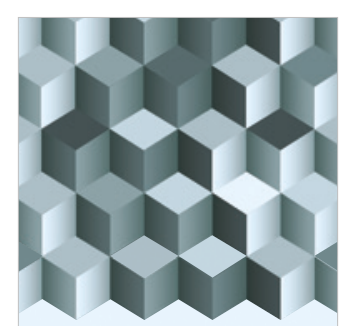

Journal of

Function Spaces
The Scientific

World Journal

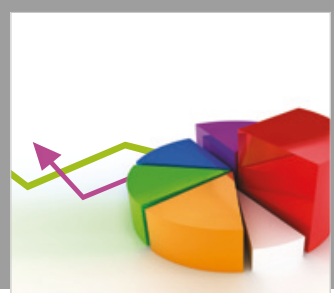

Journal of

Probability and Statistics
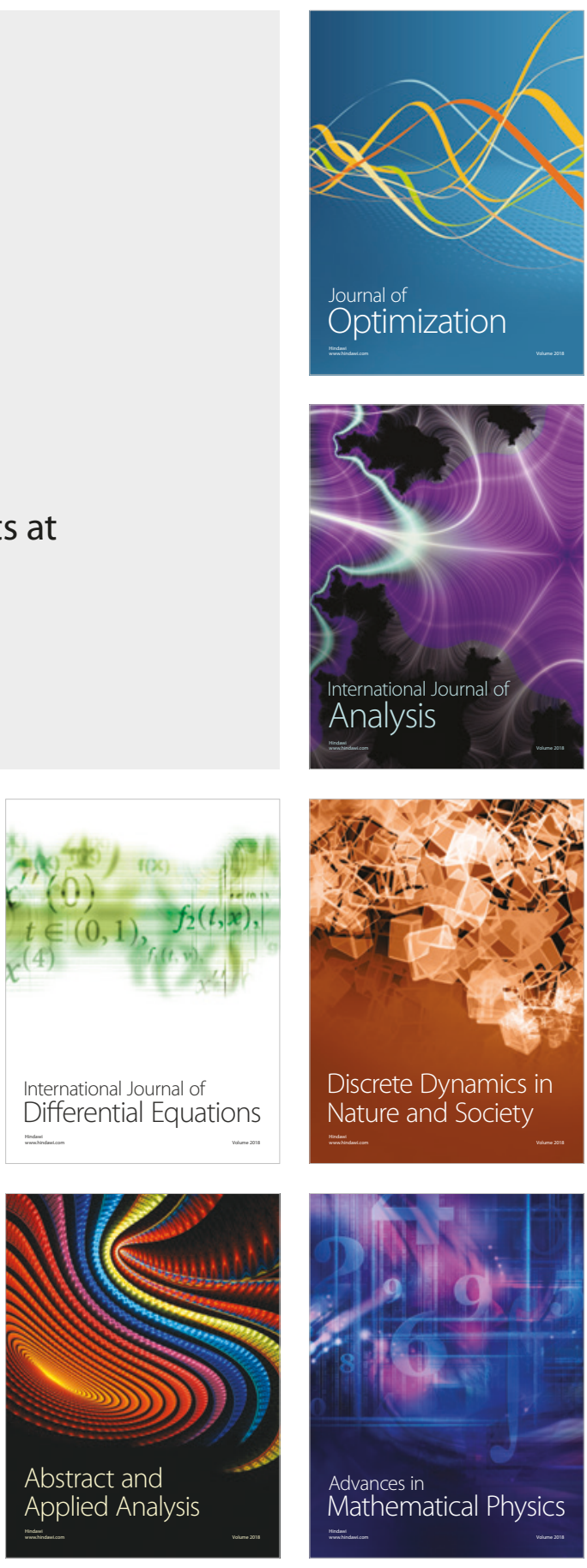